NBER WORKING PAPER SERIES

DECODING INDIA'S LOW COVID-19 CASE FATALITY RATE

\author{
Minu Philip \\ Debraj Ray \\ S. Subramanian \\ Working Paper 27696 \\ http://www.nber.org/papers/w27696 \\ NATIONAL BUREAU OF ECONOMIC RESEARCH \\ 1050 Massachusetts Avenue \\ Cambridge, MA 02138 \\ August 2020, Revised August 2020
}

We thank Dean Spears for useful comments, and Vrinda Anand for helpful assistance. Ray acknowledges research support from the National Science Foundation under Grant no. SES-1851758. The views expressed herein are those of the authors and do not necessarily reflect the views of the National Bureau of Economic Research.

NBER working papers are circulated for discussion and comment purposes. They have not been peer-reviewed or been subject to the review by the NBER Board of Directors that accompanies official NBER publications.

(C) 2020 by Minu Philip, Debraj Ray, and S. Subramanian. All rights reserved. Short sections of text, not to exceed two paragraphs, may be quoted without explicit permission provided that full credit, including $\odot$ notice, is given to the source. 
Decoding India's Low Covid-19 Case Fatality rate

Minu Philip, Debraj Ray, and S. Subramanian

NBER Working Paper No. 27696

August 2020, Revised August 2020

JEL No. J10,J11,O10,O57

\begin{abstract}
$\underline{\text { ABSTRACT }}$
India's case fatality rate (CFR) under covid-19 is strikingly low, trending from $3 \%$ or more, to a current level of around $2.2 \%$. The world average rate is far higher, at around $4 \%$. Several observers have noted that this difference is at least partly due to India's younger age distribution. In this paper, we use age-specific fatality rates from 14 comparison countries, coupled with India's distribution of covid-19 cases to "predict" what India's CFR would be with those agespecific rates. In most cases, those predictions are lower than India's actual performance, suggesting that India's CFR is, if anything, too high rather than too low. We supplement the prediction exercises with the application of a decomposition technique, and we additionally account for time lags between case incidence and death, for a more relevant cross-country perspective in the growth phase of the pandemic.

Minu Philip

Department of Economics

New York University

19 West 4th Street, 6 Floor

New York, NY 10012

minu.philip@nyu.edu

Debraj Ray

Department of Economics

New York University

19 West Fourth Street

New York, NY 10012

and University of Warwick

and also NBER

debraj.ray@nyu.edu

S. Subramanian

36-H, North Parade Road

St Thomas's Mount

Chennai, TN 600016

India

ssubramanianecon@gmail.com
\end{abstract}




\title{
Decoding India's Low Covid-19 Case Fatality Rate ${ }^{\dagger}$
}

\author{
Minu Philip, Debraj Ray and S. Subramanian ${ }^{\ddagger}$
}

July 2020

\begin{abstract}
India's case fatality rate (CFR) under covid-19 is strikingly low, trending from $3 \%$ or more, to a current level of around $2.2 \%$. The world average rate is far higher, at around $4 \%$. Several observers have noted that this difference is at least partly due to India's younger age distribution. In this paper, we use age-specific fatality rates from 14 comparison countries, coupled with India's distribution of covid-19 cases to "predict" what India's CFR would be with those age-specific rates. In most cases, those predictions are lower than India's actual performance, suggesting that India's CFR is, if anything, too high rather than too low. We supplement the prediction exercises with the application of a decomposition technique, and we additionally account for time lags between case incidence and death, for a more relevant cross-country perspective in the growth phase of the pandemic.
\end{abstract}

\section{Introduction}

As we write, India has over 2 million confirmed cases of covid-19, with a death toll of over 43,000. Figure 1 plots the corresponding case fatality rate [CFR] in India, compared to the world as a whole (Panel A) and with selected countries (Panel B). Over the initial duration of this epidemic, India has hovered around a CFR of 3\% or more, with a steady downward trend. The world rate is far higher, trending down from a peak of over $7 \%$ to a current number around $4 \%$. Several economically advanced countries are far higher still. Panel B of Figure 1 compares India to a number of other countries - these comparisons will recur through the paper. India is at or near the bottom of the case fatality heap. The end-July fatality rate of around $2.2 \%$ compares more than favorably with countries such as the Netherlands (11.5\%), Italy (14.2\%), and Spain (10\%).

Of course, case fatality rates are not to be confused with infection fatality rates, the latter being the true measure of mortality from the disease. But infection stocks are not

\footnotetext{
${ }^{\dagger}$ We thank Dean Spears for useful comments, and Vrinda Anand for helpful assistance. Ray acknowledges research support from the National Science Foundation under Grant no. SES-1851758.

$\ddagger$ Philip: New York University, minu.philip@nyu.edu, Ray: New York University and University of Warwick, debraj.ray@nyu.edu. Subramanian: Independent researcher, ssubramanianecon@gmail.com.
} 

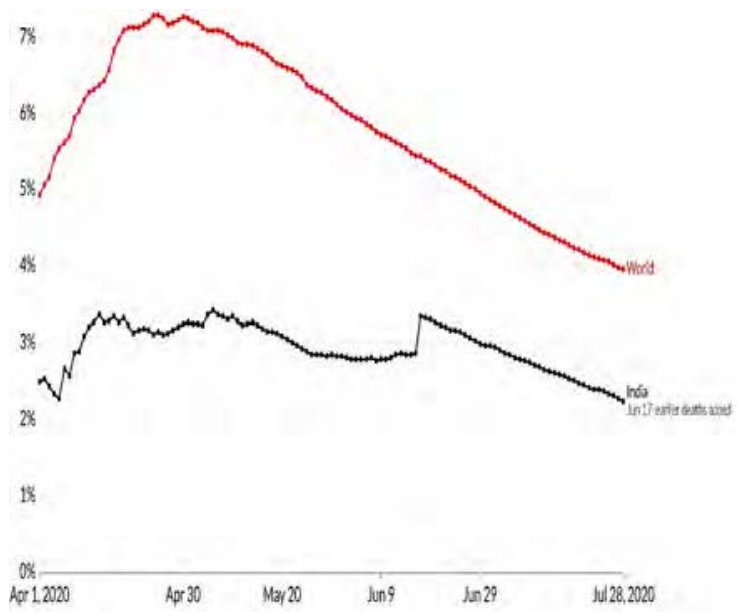

(a) India and World

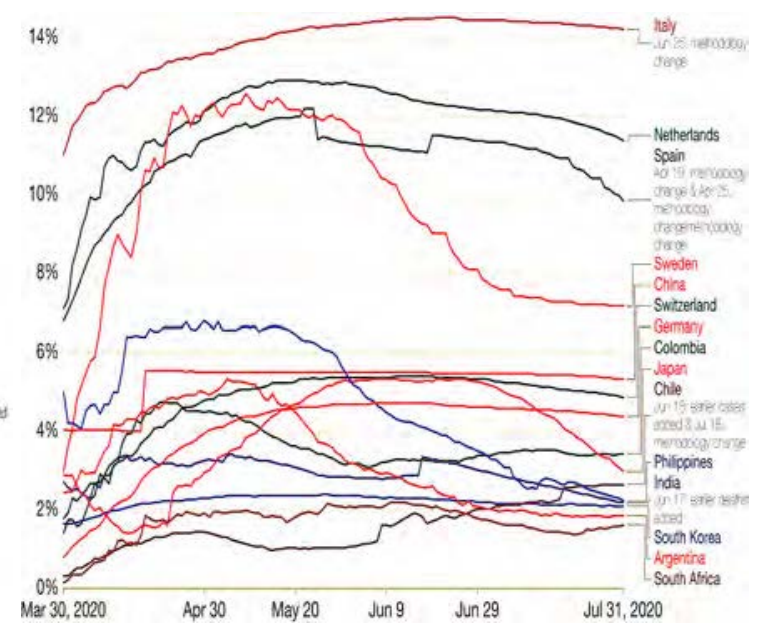

(b) India and Others

Figure 1. Case Fatality Rates for India and Selected Countries over March 30 - July 31, 2020. Source. Our World in Data, https://ourworldindata.org/.

known anywhere in the world, and in India they are currently the subject of considerable debate. ${ }^{1}$ Therefore, at least for assessing trends and comparisons, we must currently make do with CFRs. And it is not a bad measure at all for this purpose, provided that the absolute numbers are not interpreted literally, ${ }^{2}$ and are only used to make comparisons across countries and time; that too with a great deal of care.

Certainly, India's seeming robustness under this measure (compared to other countries) has not gone unnoticed by her Government. Spokespersons have tended to attribute it to "early identification and clinical management of cases." Prime Minister Modi, in a national address on July 26, 2020, while correctly emphasizing the need to "remain vigilant," observed that "India's covid-19 recovery rate is better than others. Our fatality rate is much less than most other countries."3

To move from a low CFR to an unqualified commendation of deliberate policy-induced containment of the disease might (to put it mildly) overlook certain crucial aspects of

${ }^{1}$ Bhramar Mukherjee, in private communication, suggests a nationwide underreporting factor of the order of 15-25, implying a current infected population of 30-50 million. See Bhattacharyya et al. [2] for more details on the calculation of the underrporting factor for India.

${ }^{2}$ There are many reasons why the absolute values of CFRs have no obvious and natural meaning, some of which will play an unavoidable role in this paper.

${ }^{3}$ The Hindustan Times, July 26, 2020; https://www.hindustantimes.com/india-news/pm-narendra-modi-s -67th-mann-ki-baat-address-to-nation-highlights/story-bXhnWiU1WElwNLFp0mpWRJ.html. 
demographic detail. That the age distribution within a country will influence the CFR is widely known, with "younger countries" exhibiting lower CFRs simply on account of lower death rates among younger age groups. Many observers have pointed to the Indian age structure as a possible confound in interpreting the aggregate case fatality rate; see, for instance, Ray and Subramanian [19] and Mukhopadhayay [15] for India in particular, and Dudel et al [6] for other countries. ${ }^{4}$

We take this observation as a starting point, but seek a more precise quantitative comparison between India and other countries. Sections 2-4 deal with alternative approaches to this question, so as to provide an overall assessment of India's case fatality rate under covid-19.

One way of adjusting for age-distribution in a relatively young country is to ask what would happen to that country's overall CFR if it experienced age-specific CFRs similar to those in countries in which older cohorts account for a larger share of the population. We do this for India using a set of selected comparison countries in Section 2: the same countries that appear in Figure 1.

With detailed age-specific data for both India and comparison countries, one can additionally decompose the differences in case fatality rates for a sharper description of how the distribution of cases and deaths by age affect aggregate mortality statistics. The method is different from that in Section 2, in that it precisely separates the difference in CFR into two effects: one corresponding to case distribution (an "incidence effect"), and the other to age-specific fatality rates (the "fatality effect"). The case distribution used to partition these two effects is an average of the case distribution for India and the comparison country, as opposed to just the Indian distribution; see Section 3 for details. Our approach corresponds closely to that taken by Dudel et al [6] to explain the observed cross-country variation in CFRs of selected countries. The decomposition technique that we use was introduced by Shorrocks [24] and based on the Shapley value - the so-called Shorrocks-Shapley decomposition. In the specific context of our paper, this decomposition coincides with a procedure with widespread demographic applications

\footnotetext{
${ }^{4}$ There are, of course, several other reasons for the CFR to vary across countries. Countries with higher testing rates will generally have lower CFRs - spotting more cases at an earlier and presumably milder stage. Moreover, CFRs will tend to trend down over time within the same country, as its testing improves. Actually, India is pretty low on the world testing scale as measured by per-capita tests, so this logic suggests that its CFR should be higher, not lower. There are other ancillary issues, such as obvious caveats associated with using data from multiple sources, such as definitional differences in what constitutes a "covid-19 death." There is also the question of under-reporting [18], though this will affect both numerator and denominator in the CFR.
} 
advanced by Kitagawa [13], which seeks to factorize the "difference between two rates" into its "component" parts [16]. Dudel et al [6] apply this procedure to differences in case fatality rates, as we do in this paper. We find that India's low CFR, while seemingly comparable (at least currently) to countries such as South Korea, masks significant differences in age-specific incidence and mortality burdens from those of South Korea, and only appears to be of comparable magnitude by a serendipitous opposition of these factors in the process of aggregation.

All of the preceding analysis is based on the presumption that reported CFR figures are to be accepted at face-value. But what if the CFR as usually reported should turn out to be an inappropriate representation of the actual case fatality rate? Such a contingency arises from a closer reading-when covid infection results in death-of the time-lag that typically occurs between the onset of infection and the date of death. Verity et al [27] report a mean duration of around 18 days from infection to death (in cases where death occurs). ${ }^{5}$ It is unclear when such cases would be registered as "confirmed" - that would depend on testing times - but in any event, cumulative deaths should be related to cumulative cases at some anterior date. This suggests that the contemporaneous CFR - the number of covid deaths on a given date divided by the number of covid cases as on that date - might be an inaccurate reflection of the actual covid case mortality rate, which could be better approximated by a "lagged" CFR. A better approximation is the number of covid deaths on a particular date divided by the number of covid cases at some relevant lag before that date. With cases mounting over time, the contemporaneous CFR will understate case fatality relative to the lagged CFR. That would be true for all countries, but the extent of underestimation would be different for different countries because of inter-country variation in the rate of growth of cases. Section 4 undertakes a comparison of India with selected countries, while exploring the difference between contemporaneous and lagged CFRs.

To summarize: there are two potential sources of difficulty in simply accepting the case fatality rate, as it is usually reported, as a reliable indicator of cross-country comparison. (This is quite separate from the inadequacy of case fatality rates as a true measure of covid-19 fatality, a well-known issue that we do not address here.) The first has to do with the failure of the measure to reflect the precise age-distribution of cases and deaths that obtains in each particular situation under study. The second has to do with the

\footnotetext{
${ }^{5}$ Based on a Chinese study by Yang et al (2020), Wilson et al (2020) conclude that ". . . a median of 13 days passed from pneumonia confirmation to death..."
} 
strong possibility that a lagged CFR is a more dependable indicator of case fatality than the customary contemporaneous CFR. Correcting for these complications, as we shall see, leads to a picture of India's health-related capability in dealing with the covid-19 epidemic which is altogether less flattering than what might otherwise appear to be the case. This is one more instance of the general proposition that careful measurement can make a difference to our assessment of actual country performance in the matter of human development and capabilities.

\section{Predicting Indian Mortality from Age-Specific CFRs of Other Countries}

To fix some elementary ideas and notation: let $f^{c}$ be the overall CFR in any country $c, f_{j}^{c}$ the CFR in age-group $j$, and let $w_{j}^{c}$ be the proportion of all cases in age-group $j$. Then, for any country,

$$
f^{c}=\sum_{j=1}^{M} w_{j}^{c} f_{j}^{c},
$$

where $M$ is the number of age groups. Begin by looking at India's weight distribution $\left\{w_{j}^{I}\right\}$, which marks the incidence of the disease across different age groups. Figure 2 displays information on the population distribution by age, the weight distribution by age, and the impact ratios, which we define to be $w_{j}^{c} / n_{j}^{c}$, where $n_{j}^{c}$ is the population share in age group $j$ for country $c$. These objects are displayed in Table 1 . The first

\begin{tabular}{lrrrrrrrrr}
\hline \multicolumn{10}{c}{ Age Group } \\
\hline & $\mathbf{0 - 9}$ & $\mathbf{1 0 - 1 9}$ & $\mathbf{2 0 - 2 9}$ & $\mathbf{3 0 - 3 9}$ & $\mathbf{4 0 - 4 9}$ & $\mathbf{5 0 - 5 9}$ & $\mathbf{6 0 - 6 9}$ & $\mathbf{7 0 - 7 9}$ & $\mathbf{8 0 +}$ \\
Case \% [1] & 3.6 & 8.1 & 21.5 & 21.0 & 16.8 & 14.2 & 9.9 & 3.8 & 1.1 \\
Pop \% [2] & 19.8 & 20.9 & 17.6 & 14.4 & 11.1 & 7.3 & 5.3 & 2.4 & 0.9 \\
Impact [1/2] & 0.2 & 0.4 & 1.2 & 1.5 & 1.5 & 2.0 & 1.9 & 1.6 & 1.2 \\
\hline
\end{tabular}

Table 1. Case incidence, population distribution and impact ratios in India. The impact ratios show how different ages are affected relative to population share. Sources. Case distribution from [7]. Population age distribution from 2011 Indian Census.

exercise that we conduct is to "predict" case fatality rates for India using age-specific data from a set of comparison countries, but using weights from the case distribution pertaining to India. The idea is to approximate how India would perform if it had the age-specific case fatality rates of these comparison countries. As it happens, our set of comparisons is perforce limited because information on cases and deaths by age is 


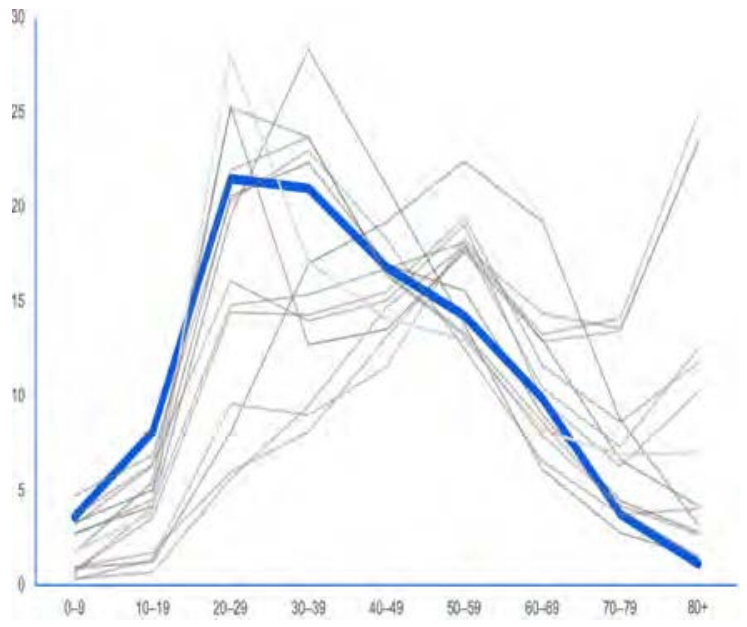

(a) Cases by Age

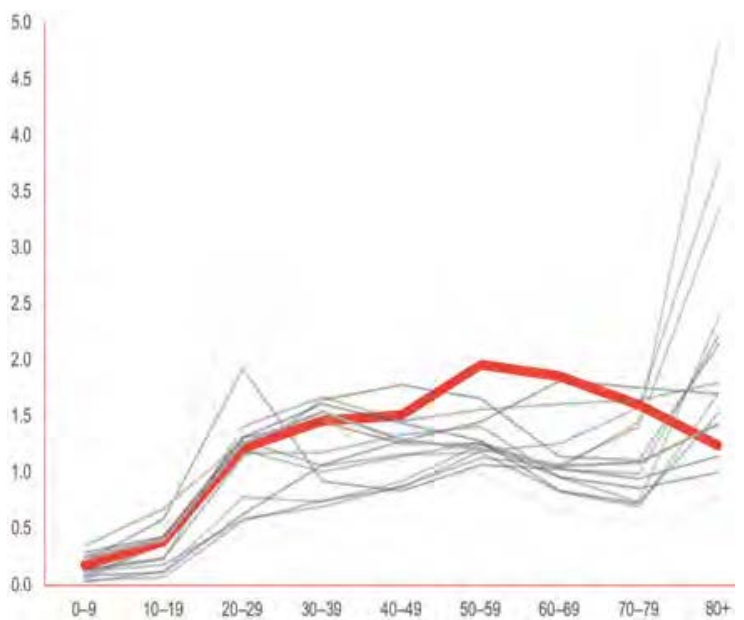

(b) Impact Ratios by Age

Figure 2. Cases and Impact Ratios by Age for India and Selected Countries. Panel A shows the percentage of cases in each age group by country, Panel B plots the impact ratio the ratio of case percentage to population percentage by age, by country. A ratio greater than 1 indicates that the age group in question has been disproportionately hit relative to population size. In each panel, India is shown in bold; comparison countries are as listed in Table 2. Sources. Case Distribution (see Table 7) from sources listed under Appendix 5.5. Population distribution calculated using UN World Population Prospects [26].

not easy to come by and needs to be extracted from individual country dashboards. Many countries do not provide those data or (as in the case of India) do so infrequently and irregularly via Ministerial decree. As of August 4, the Wikipedia website https: //en.wikipedia.org/wiki/Coronavirus_disease_2019 lists 22 countries with age-specific, countrylevel mortality rates, of which we use 14: Argentina, Chile, China, Colombia, Germany (Bavaria), Italy, Japan, the Netherlands, the Philippines, South Africa, South Korea, Spain, Sweden and Switzerland. ${ }^{6}$

Figure 2A shows the percentage of covid-19 cases by age group for India and the comparison countries, with the Indian line depicted in boldface. Relative to our comparison list - with the exception of other developing countries such as South Africa - India is a very young country indeed. The Indian case distribution by age

${ }^{6}$ The remaining 8 countries are Australia, Canada, Denmark, Finland, Israel, Mexico, Norway and Portugal, and including them does not affect the analysis but lengthens the tables without much added insight. 
sharply falls upon the younger age groups: the corresponding lines for several of the comparison countries are shifted to the right.

What is less obvious is the pattern shown in Panel B. That panel plots the impact ratio - the ratio of case incidence to population percentage by age, by country. A ratio greater than 1 indicates that the age group in question has been disproportionately hit relative to population size. India is shown in bold. For all countries, the impact ratios are smaller than one for the youngest age group, which is only to be expected: after all, the very youngest are relatively isolated from widespread and anonymous social interaction. But among working adult groups and relative to the comparison countries, India stands out in having a large impact ratio. These middle-aged working groups are not only those excessively represented in overall population (Panel A), they are also disproportionately more affected by covid-19. The impact ratio is closer to 1 for the oldest age groups, while for many of the comparison countries, that impact ratio spikes upward quite dramatically. Taken together, these two features (population distribution and the distribution of impact ratios) create a substantial skew, at least in the measured incidence of covid-19, among the younger age groups. ${ }^{7}$ For the exact distributions of cases and deaths by age for our comparison countries, see Table 7 in the Appendix.

These distributions come from a variety of dates for different countries. Unfortunately, for countries for which age-based mortality data is taken from data visualization dashboards, previous information often disappears from the visualization once updated, so that we typically have access to age-specific data at one date, that of the latest update. But there are exceptions. These suggest that barring the initial phases of the pandemic, the distribution of cases and deaths across ages appears to be reasonably stable. We explore this stability in Appendix 5.3. That is not true of the age-specific mortality rates, which do change significantly over time. But the point is that the latter changes because there has been significant movement in the case-fatality rate over time, and not because the relative dispersion of cases or deaths has been changing. This feature will be exploited in the analysis below.

We can use India's case distribution information, along with the CFR patterns from comparison countries, to "predict" India's CFR were it to be driven by the age-specific rates in those countries, coupled with India's case distribution across ages (which mirrors Indian demographics). Table 2, which significantly extends Table 3 in Ray

\footnotetext{
${ }^{7}$ It is possible that relative to the comparison countries, the old die at home in India, and covid deaths are disproportionately undercounted among them.
} 


\begin{tabular}{lrrrrr}
\hline & \multicolumn{5}{c}{ Dates } \\
& June 20 & June 30 & July 10 & July 20 & July 30 \\
\hline India & $\mathbf{3 . 2 8}$ & $\mathbf{2 . 9 8}$ & $\mathbf{2 . 7 2}$ & $\mathbf{2 . 4 6}$ & $\mathbf{2 . 2 1}$ \\
China & 2.85 & 2.84 & 2.84 & 2.82 & 2.78 \\
S. Korea & 1.08 & 1.05 & 1.03 & 1.10 & 1.00 \\
Japan & 2.29 & 2.24 & 2.03 & 1.68 & 1.32 \\
Philippines & 4.07 & 3.53 & 2.61 & 2.78 & 2.35 \\
\hline Netherlands & 2.46 & 2.43 & 2.42 & 2.37 & 2.29 \\
Italy & 3.18 & 3.16 & 3.15 & 3.14 & 3.11 \\
Spain & 2.44 & 2.41 & 2.37 & 2.27 & 2.11 \\
Bavaria & 1.94 & 1.94 & 1.92 & 1.90 & 1.87 \\
Sweden & 2.43 & 2.11 & 1.99 & 1.95 & 1.93 \\
Switzerland & 1.34 & 1.33 & 1.29 & 1.26 & 1.22 \\
\hline S. Africa & 2.47 & 2.07 & 1.85 & 1.63 & 1.88 \\
Chile & 1.35 & 1.55 & 1.67 & 1.97 & 2.02 \\
Colombia & 2.89 & 3.03 & 3.14 & 3.05 & 3.06 \\
Argentina & 2.02 & 1.68 & 1.60 & 1.50 & 1.51 \\
\hline
\end{tabular}

Table 2. Predicted Indian CFRs. Numbers in each column report a counterfactual CFR for India predicted using age-specific CFRs of the respective comparison country and India's case distribution (Table 1). Sources. Case and Death Distributions (Table 7) from sources listed under Appendix 5.5 combined with CFRs from [20] to calculate age-specific CFRs.

and Subramanian [19], carries out these predictive exercises. Specifically, country c's prediction for India can be written as

$$
\hat{f^{c}, I}=\sum_{j=1}^{M} w_{j}^{I} f_{j}^{c},
$$

where the weights are the Indian distribution of cases across the population.

India's latest CFR numbers stand at around 2.2\%, but as Figure 1 also reveals, India's CFR has been around 3\% for much of the period since the start of the pandemic, hitting $3.4 \%$ on June 17 as an adjustment of past deaths was made in the database; then falling slowly. Depending on the dates for counterfactual prediction - we use five - we have different rates for India, which are described in Table 2. Countries that (age-adjusted with Indian weights) predict a lower CFR - relative to India's actual aggregate CFR - are shown in blue. Note that some country-level observations are mixed over time. The adjusted CFRs in Table 2 are quite remarkable, given that the actual CFRs for many 
of these countries far exceed those of India (Figure 1, Panel B). Countries such as the Netherlands or Spain have a CFR well in excess of $10 \%$. And yet, once adjusted for the Indian case distribution, it becomes clear that India is no longer an outlier. While the reader is invited to go through the individual comparisons, we single out South Korea here, because age-unadjusted, the two CFRs are comparable. And yet, once we adjust for differences in the demographic distribution, the South Korean rates translate into an aggregate CFR of merely $0.74 \%$, far lower than India's current CFR of around $2.3 \%$.

The over-predictors are the Philippines, Colombia and more recently China - and Italy, which in the light of the European figures, comes as a bit of a (relative) surprise. ${ }^{8}$ Compared to these countries, India's performance does not look as bad. We will revisit these outliers when we study lagged fatalities in Section 4. On the whole, and given the existing data limitations, it appears safe to label as exaggeration the assertion that India's "fatality rate is much less than most other countries."

\section{Decomposing Inter-Country Differences in Case Fatality Rates}

3.1. A Decomposition. For a meaningful comparison of CFRs across two countries, we decompose the difference in CFRs into what may be called a fatality effect and an caseincidence effect. Let $I$ stand for India, our country of interest, and let $C$ be any comparison country. We "decomposing" this difference into two terms, as follows:

$$
\begin{aligned}
f^{c}-f^{I} & =\frac{1}{2}\left(f^{c}-f^{I}\right)+\frac{1}{2}\left(f^{c}-f^{I}\right) \\
& =\frac{1}{2}\left(f^{c}-\sum_{j=1}^{M} w_{j}^{I} f_{j}^{c}+\sum_{j=1}^{M} w_{j}^{c} f_{j}^{I}-f^{I}\right)+\frac{1}{2}\left(f^{c}+\sum_{j=1}^{M} w_{j}^{I} f_{j}^{c}-\sum_{j=1}^{M} w_{j}^{c} f_{j}^{I}-f^{I}\right) \\
& =\frac{1}{2}\left[\sum_{j=1}^{M}\left(w_{j}^{c}-w_{j}^{I}\right)\left(f_{j}^{c}+f_{j}^{I}\right)\right]+\frac{1}{2}\left[\left(\sum_{j=1}^{M}\left(w_{j}^{c}+w_{j}^{I}\right)\left(f_{j}^{c}-f_{j}^{I}\right)\right]\right. \\
& =\frac{1}{2}\left[\sum_{j=1}^{M} \Delta w_{j}\left(f_{j}^{c}+f_{j}^{I}\right)\right]+\frac{1}{2}\left[\sum_{j=1}^{M}\left(w_{j}^{c}+w_{j}^{I}\right) \Delta f_{j}\right],
\end{aligned}
$$

\footnotetext{
${ }^{8}$ The Italian comparison exhibits some contrast to Mukhopadhyay's analysis; see [15]. He undertakes a similar exercise as in Table 2 using Italian data, and reports that: "[B]y multiplying Italy's age-specific CFR ... to the age-specific number of cases in India, [we find that] [t]he estimated numbers of deaths that should have occurred, if the age-specific death rates of Italy were to prevail in India, is 535 . The official number of deaths in India as of April 30 was actually twice that number, at 1074." We go some way towards a resolution of this difference in Section 4, though the disparity is still puzzling.
} 
where $\Delta w_{j}=w_{j}^{c}-w_{j}^{I}$, and $\Delta f_{j}=f_{j}^{c}-f_{j}^{I}$. This decomposition is an instance of the Shapley procedure described by Shorrocks [24], based on Shapley's [23] formulation of his celebrated "value" as a solution to allocation problems within a cooperative game. As noted earlier, this decomposition also corresponds exactly — within our demographic context — with the procedure advanced by Kitagawa [13], and applied to the case fatality rate by Dudel et al [6]. Note that this is an exact decomposition procedure, that is, the relative contributions of the factors driving the change under examination add up to exactly one hundred per cent (without leaving behind any hard-to-interpret residual effects, such as the so-called "interaction" effect in "standard" decompositions).

The first component in the decomposition (1) is what we might call the incidence effect. It quantifies the difference in CFRs that would arise solely due to age-specific differences in case incidence rates under the hypothetical scenario that the countries share the average of their age-specific CFRs. This number will typically be positive if the comparison country is older, because the older age groups are weighted by higher fatality rates, and the comparison country will have more of such groups.The second component, which we call the fatality effect, quantifies the difference in CFRs that would arise solely due to differences in age-specific CFRs, in the hypothetical scenario that the countries share the average of their age-specific infection rates. This number would be negative if India's age-based fatality rate is higher than the corresponding age-based fatality rate for the comparison country, at most or all age groups.

The fatality effect is closely related to the analysis in Table 2, where we "predict" Indian CFR using India's case distribution. The fatality effect can be thought of as a similar exercise, but in this case we use as weights the average of the case distribution for India and the comparison country in question. Because the economically advanced countries among the latter group are more likely to have an older population, this tempers the prediction somewhat, and we expect milder effects compared to Table 2.

3.2. Decomposing India's CFR. The use of the decomposition formula relies on more data than in Section 2. Specifically, we also need deaths by age for India, a statistic that is released sporadically by the Union Health Ministry and in age brackets that are both coarse and frustratingly non-comparable with those used for our comparison countries. The latest numbers are from a July 8 Press Release, with death incidence for six age brackets. To maintain comparability, we've split these brackets into the narrow nine 
brackets used so far, drawing on additional data and using an interpolation procedure fully described in Appendix 5.2. The results are reported in Table 3.

\begin{tabular}{lrrrrrrrrr}
\hline & \multicolumn{10}{c}{ Age Group } \\
\hline & $\mathbf{0 - 9}$ & $\mathbf{1 0 - 1 9}$ & $\mathbf{2 0 - 2 9}$ & $\mathbf{3 0 - 3 9}$ & $\mathbf{4 0 - 4 9}$ & $\mathbf{5 0 - 5 9}$ & $\mathbf{6 0 - 6 9}$ & $\mathbf{7 0 - 7 9}$ & $\mathbf{8 0 +}$ \\
Cases (\%) & 3.6 & 8.1 & 21.5 & 21.0 & 16.8 & 14.2 & 9.9 & 3.8 & 1.1 \\
Deaths (\%) & 0.8 & 0.9 & 2.4 & 5.5 & 13.5 & 24.0 & 30.4 & 15.7 & 6.7 \\
\hline
\end{tabular}

Table 3. Case and Death Distribution by Age for India. Sources. Case distribution from [7], identical to that in Table 1. Death distribution interpolated using Indian Ministry of Health Press Release, July 08, 2020 (details in Appendix 5.2).

Armed with the information here and invoking analogous data (see Table 7) for the comparison countries, we can set equation (1) to work. The results are reported in Table 4. The table studies three dates over which the Indian CFR has progressively fallen (and, in general, so have those of the comparison countries). For each of these dates and each comparison country, we report the CFR of the country, which - barring a couple of cases - significantly exceeds those of India. The decomposition exercise then breaks up the difference between the Indian and comparison CFR into incidence and fatality effects, as described in (1). The CFR difference is the sum (accounting for positive and negative values) of the incidence and fatality effects.

Once again let's single out South Korea, given that its CFR on July $30(2.1 \%)$ is comparable with that of India (2.2\%). But this comparability is the coincidental cancelation of two strongly opposing forces. The incidence effect is positive. As already discussed, this comes from the fact that South Korea has an older population. So the fatality-weighted distribution of cases generates a higher fatality for South Korea on that score. But the fatality effect is negative - that is, the case-weighted distribution of fatalities generates a larger number for India. The two effects cancel, leaving them with comparable CFRs on the aggregate. The higher age-specific fatality rate, as indicated by the negative fatality effect, is suggestive of a relatively lower level of robustness of health in India, or a relatively lower level of robustness of treatment facilities, or both. The decomposition of the difference in their CFRs confirms our assessment. If India and South Korea shared their age-specific CFRs, their average, South Korea's aggregate CFR would be higher than India's by close to one percentage point, a huge difference relative to their baseline 


\begin{tabular}{lrrrr|rrrr|rrrr}
\hline \multicolumn{7}{c}{ 20 June } & \multicolumn{3}{c}{ 10 July } & & \multicolumn{3}{c}{ 30 July } \\
Country & CFR & Diff & IE & FE & CFR & Diff & IE & FE & CFR & Diff & IE & FE \\
\hline India & 3.28 & 0 & - & - & 2.72 & 0 & - & - & 2.21 & 0 & - & - \\
China & 5.49 & 2.21 & 2.52 & -0.31 & 5.46 & 2.74 & 2.31 & 0.43 & 5.34 & 3.13 & 2.09 & 1.04 \\
South Korea & 2.26 & -1.02 & 1.24 & -2.26 & 2.16 & -0.56 & 1.11 & -1.67 & 2.10 & -0.11 & 0.99 & -1.10 \\
Japan & 5.35 & 2.07 & 2.14 & -0.07 & 4.74 & 2.02 & 1.86 & 0.16 & 3.09 & 0.88 & 1.29 & -0.41 \\
Philippines & 3.97 & 0.69 & -0.08 & 0.78 & 2.55 & -0.17 & -0.06 & -0.11 & 2.30 & 0.09 & -0.05 & 0.14 \\
Netherlands & 12.30 & 9.02 & 7.83 & 1.19 & 12.08 & 9.36 & 7.25 & 2.11 & 11.46 & 9.25 & 6.55 & 2.71 \\
Italy & 14.52 & 11.24 & 8.78 & 2.46 & 14.41 & 11.69 & 8.21 & 3.48 & 14.24 & 12.03 & 7.65 & 4.37 \\
Spain & 11.52 & 8.24 & 7.54 & 0.70 & 11.19 & 8.47 & 6.90 & 1.57 & 9.97 & 7.76 & 5.95 & 1.81 \\
Bavaria & 5.37 & 2.09 & 2.82 & -0.73 & 5.32 & 2.60 & 2.62 & -0.02 & 5.16 & 2.95 & 2.39 & 0.56 \\
Sweden & 9.02 & 5.74 & 4.71 & 1.03 & 7.40 & 4.68 & 3.88 & 0.80 & 7.18 & 4.97 & 3.58 & 1.40 \\
Switzerland & 5.37 & 2.09 & 3.53 & -1.43 & 5.18 & 2.46 & 3.20 & -0.74 & 4.90 & 2.69 & 2.86 & -0.16 \\
South Africa & 2.09 & -1.19 & -0.35 & -0.84 & 1.56 & -1.16 & -0.28 & -0.88 & 1.59 & -0.62 & -0.25 & -0.36 \\
Chile** & 1.77 & -1.51 & 0.41 & -1.92 & 2.18 & -0.54 & 0.42 & -0.96 & 2.64 & 0.43 & 0.44 & -0.01 \\
Colombia & 3.23 & -0.05 & 0.22 & -0.27 & 3.52 & 0.80 & 0.23 & 0.57 & 3.42 & 1.21 & 0.22 & 1.00 \\
Argentina & 2.48 & -0.80 & 0.31 & -1.12 & 1.96 & -0.76 & 0.25 & -1.01 & 1.85 & -0.36 & 0.23 & -0.59 \\
\hline
\end{tabular}

Table 4. CFR-Difference Decomposition For India and Comparison Countries. Sources. Distribution of cases and deaths from Tables 3 and 7. These, along with overall CFRs from[20], are combined and applied to the decomposition formula (1) to obtain Incidence Effects (IE) and Fatality Effects (FE).

CFRs. Alternatively, with the same case distribution, South Korea's CFR would be lower by one percentage point, owing to its low age-specific CFRs.

The near-equivalence in the two CFRs is therefore manufactured by aggregation, occurring despite a fatality effect that goes against a favorable welfare interpretation for India, from which the country is rescued by its particular pattern of the age-distribution of covid-19 incidence. The same pattern occurs for a number of comparison countries.

This decomposition analysis goes beyond our earlier comparisons in Table 2, in that it also includes the counterfactual when the CFRs are the same but case incidence isn't. Here, India's "advantage" of higher case incidence among the young is not by virtue of its demographic characteristics alone. A quick recall of the population shares and case shares in Table 1, along with Panel B of Figure 2, reminds us that the caseload for the working-age population in India is higher than its population share. In contrast to most other countries with the highest impact ratio reserved for the oldest age group, it is the impact ratio for the middle-aged and older working population that is relatively high in India. While this helps attenuate India's CFR, this is certainly not desirable otherwise. Why that population is disproportionately affected requires an evaluation of exposure, 
prevalence of co-morbidities, or lifestyle choices such as smoking, which is beyond the scope of the present exercise.

All in all, the recipe for a low aggregate CFR looks quite simple to implement: pick either an endowment of low age-specific CFRs, or a case distribution skewed towards low-CFR age groups. India's demographic structure generates an abundant supply of the second ingredient, amplified by its high impact ratios for working-age groups. (The same is true of South Africa, another young country.) In contrast, India appears to be lacking in the first ingredient: low age-specific CFRs.

Comparisons such as those between India and South Korea are not intended to verify the easily accessed fact that India has fared poorly in relation to a country which is an obvious outlier. Such comparisons would then add up to no more than an essentially trite exercise. Rather, the objective, at a general level, is to drive home the point that social indicators such as the aggregate CFR are essentially outcome-indicators, and that in certain cases, similar outcomes (as for India and South Korea) can display widely differing underlying processes that lead up to these outcomes. Similar observations have been made by Anderson and Ray [1] and Jayaraj and Subramanian [11] about the sex-ratio of a population, and by Mukherji and Kanbur [12] about poverty indices. This general point reinforces the specific desirability of guarding against misplaced complacence (or panic, as the case may be) that could arise from an exclusive concern with the sheer external magnitude of a statistic such as the CFR.

\section{Growing Epidemics and Lagged Case Fatality Rates}

When a covid-19 infection ends in death, the mean duration from symptoms to death is a bit more than two weeks; see, for instance, Verity et al [27], who report a mean duration of around 18 days. It is unclear when such cases would be registered as "confirmed" before the death occurs - that would depend on when testing occurs after the onset of symptoms - but it is likely that the cumulative deaths at any date should be related to cumulative cases at some anterior date, and not cumulative contemporaneous cases.

How anterior that date should be is obviously open to debate. Using case counts from January 30, 2020 to May 14, 2020, Mohanty et al [14] find that the 14-day lagged CFR (LCFR) for India is $8.01 \%$, more than twice the contemporaneous CFR of $3.70 \%$ on May 14, 2020 [9]. The hike-up would be smaller if case discovery occurred a week after symptoms - one would then use a 10-day lagged CFR. But it is no surprise, anyway, 
to learn that in societies with growing incidence (or expansion of testing), LCFR would significantly exceed CFR. That doesn't require us to calculate anything.

A more interesting question emerges when we make comparisons across countries. Every LCFR would exceed its contemporaneous counterpart. The question is: by how much? It is easy to see that ceteris paribus, a country with a faster growth rate of confirmed cases would exhibit a higher ratio of LCFR to CFR. A bit more formally, if we denote the $x$-day growth rate of cases in country $c$ by $g^{c}$, where $x$ is a number that we would need to settle upon, then lagged fatality $\phi^{c}$ is connected to contemporaneous fatality $f^{c}$ by the obvious identity:

$$
\phi^{c}=f^{c}\left[1+g^{c}\right] .
$$

4.1. The Prediction Exercise of Section 2 Revisited, with Lagged CFR. We revisit two exercises with lagged case fatality rates. The first is the prediction exercise from Table 2. That is, we use the same set of comparison countries to predict the case fatality rate for India using India's age distribution coupled with the age-specific fatality rates for those countries. But we now do so using lagged fatality rates. The following qualifications and remarks should be noted.

First, we'd like to use age-specific growth rates to achieve the correction, but this is data we do not have, so we apply the same growth rate in cases to all age groups within a country. Second, the growth rate - and consequently the predictions - will vary with the lag. Therefore, while we report 14-day lags, we explore a 10-day alternative in Appendix 5.4. Third, the choice of calendar date will matter, as it will affect not just the values of India's case fatality rate, but also the rate of growth of cases. Therefore we conduct three exercises: for June 20, July 10 and July 30. As in Table 2, we hold fixed the distribution of cases and deaths across ages. (We again refer the reader to Appendix 5.3 for the intertemporal stability of these distributions.) The age-specific lagged CFRs are generated from aggregate fatality rates applied to these distributions, and then used to make the Indian predictions. Finally, we reiterate that the specific values of the LCFRs, while potentially of interest, are problematic to interpret. We know they will go up with the lag, but their absolute magnitudes could reflect either changes in the progression of the epidemic, or the intensity of testing. Rather, all we do is explore what this does to the under- or over-prediction of India's correspondingly lagged rate. 


\begin{tabular}{lrrrrrrrrr}
\hline & \multicolumn{1}{c}{ Date-Lag Combinations } \\
& \multicolumn{3}{c}{ June 20 } & \multicolumn{3}{c}{ July 10 } & \multicolumn{3}{c}{ July 30 } \\
Country & 0 & -10 & -14 & 0 & -10 & -14 & 0 & -10 & -14 \\
\hline India & $\mathbf{3 . 2 8}$ & $\mathbf{4 . 6 8}$ & $\mathbf{5 . 4 7}$ & $\mathbf{2 . 7 2}$ & $\mathbf{3 . 8 1}$ & $\mathbf{4 . 4 1}$ & $\mathbf{2 . 2 1}$ & $\mathbf{3 . 1 3}$ & $\mathbf{3 . 6 1}$ \\
China & 2.85 & 2.86 & 2.86 & 2.84 & 2.84 & 2.85 & 2.78 & 2.83 & 2.84 \\
South Korea & 1.08 & 1.12 & 1.14 & 1.03 & 1.07 & 1.09 & 1.00 & 1.04 & 1.05 \\
Japan & 2.29 & 2.36 & 2.38 & 2.03 & 2.26 & 2.31 & 1.32 & 1.71 & 1.87 \\
Philippines & 4.07 & 5.03 & 5.61 & 2.61 & 3.71 & 4.09 & 2.36 & 2.98 & 3.41 \\
Netherlands & 2.46 & 2.54 & 2.58 & 2.42 & 2.44 & 2.46 & 2.29 & 2.38 & 2.40 \\
Italy & 3.18 & 3.21 & 3.22 & 3.15 & 3.18 & 3.19 & 3.12 & 3.14 & 3.16 \\
Spain & 2.44 & 2.48 & 2.49 & 2.37 & 2.41 & 2.43 & 2.11 & 2.28 & 2.33 \\
Bavaria & 1.94 & 1.95 & 1.96 & 1.92 & 1.95 & 1.96 & 1.86 & 1.90 & 1.91 \\
Sweden & 2.43 & 2.96 & 3.17 & 1.99 & 2.19 & 2.32 & 1.93 & 1.99 & 2.02 \\
Switzerland & 1.34 & 1.35 & 1.36 & 1.29 & 1.33 & 1.33 & 1.22 & 1.27 & 1.28 \\
South Africa & 2.47 & 4.09 & 4.99 & 1.84 & 3.05 & 3.71 & 1.88 & 2.44 & 2.85 \\
Chile & 1.36 & 2.20 & 2.56 & 1.67 & 1.85 & 1.98 & 2.02 & 2.14 & 2.21 \\
Colombia & 2.89 & 4.34 & 4.99 & 3.15 & 4.43 & 5.23 & 3.06 & 4.28 & 5.11 \\
Argentina & 2.02 & 3.24 & 3.81 & 1.60 & 2.24 & 2.66 & 1.51 & 2.13 & 2.44 \\
\hline
\end{tabular}

Table 5. Predicted Indian Lagged CFRs. Numbers in the first row report Indian LCFR for different dates and lags (10, 14 day). Subsequent rows record predictions from comparison countries. Underpredicting countries in blue, overpredicting countries in red. Sources. The same data as in Table 2 were used to build age-specific information, and in addition Our World in Data was used to estimate growth in cases.

Table 5 reports the results. First, as expected, lagged CFRs are generally sizably larger than contemporaneous CFRs. The 14-day growth in cases in India was between $60-80 \%$, which leads to higher (and probably more accurate) estimates of case fatalities; these are recorded in the first row of the table, along with the unlagged CFRs for easy comparison. The predicted rates from comparison countries are recorded in the rows below. For some countries like South Korea, Spain and Switzerland, the resulting changes are minimal, because there is a near-cessation of growth in new cases during this period. But more generally, there is a significant increase in under-prediction once the differential case growth is taken into account. For instance, Italy now switches from being an overpredictor of India's case fatality rate to being an under-predictor. The point is that Italian cases have grown slower than Indian cases during this time period, so India's effective case fatality rate is significantly higher than the rates in Table 2 . The same switch occurs for China and the Philippines, the former comfortably so given that there 


\begin{tabular}{|c|c|c|c|c|c|c|c|c|c|c|c|c|}
\hline \multirow[b]{2}{*}{ Country } & \multicolumn{4}{|c|}{20 June } & \multicolumn{4}{|c|}{10 July } & \multicolumn{4}{|c|}{30 July } \\
\hline & LCFR & Diff & IE & $\mathrm{FE}$ & LCFR & Diff & IE & $\mathrm{FE}$ & LCFR & Diff & IE & $\mathrm{FE}$ \\
\hline India & 5.47 & 0.00 & - & - & 4.41 & 0.00 & - & - & 3.61 & 0.00 & - & - \\
\hline China & 5.51 & 0.04 & 3.33 & -3.30 & 5.48 & 1.07 & 2.94 & -1.86 & 5.47 & 1.86 & 2.64 & -0.78 \\
\hline S. Korea & 2.39 & -3.08 & 1.71 & -4.80 & 2.29 & -2.12 & 1.48 & -3.60 & 2.20 & -0.41 & 1.30 & -2.70 \\
\hline Japan & 5.57 & 0.10 & 2.61 & -2.51 & 5.40 & 0.99 & 2.36 & -1.37 & 4.38 & 0.77 & 1.92 & -1.15 \\
\hline Philippines & 5.48 & 0.01 & -0.13 & 0.14 & 3.99 & -0.42 & -0.10 & -0.32 & 3.33 & -0.28 & -0.08 & -0.20 \\
\hline Netherlands & 12.90 & 7.43 & 10.02 & -2.60 & 12.29 & 7.88 & 8.83 & -0.95 & 11.99 & 8.38 & 8.00 & 0.38 \\
\hline Italy & 14.74 & 9.27 & 10.95 & -1.68 & 14.57 & 10.16 & 9.87 & 0.30 & 14.43 & 10.82 & 9.06 & 1.76 \\
\hline Spain & 11.74 & 6.27 & 9.63 & -3.37 & 11.46 & 7.05 & 8.55 & -1.50 & 10.99 & 7.38 & 7.63 & -0.26 \\
\hline Bavaria & 5.42 & -0.05 & 3.58 & -3.63 & 5.41 & 1.00 & 3.22 & -2.21 & 5.29 & 1.68 & 2.91 & -1.23 \\
\hline Sweden & 11.77 & 6.30 & 6.66 & -0.36 & 8.61 & 4.20 & 5.04 & -0.84 & 7.49 & 3.88 & 4.29 & -0.41 \\
\hline Switzerland & 5.44 & -0.03 & 4.56 & -4.59 & 5.38 & 0.97 & 4.04 & -3.07 & 5.15 & 1.54 & 3.59 & -2.05 \\
\hline S. Africa & 4.22 & -1.25 & -0.66 & -0.60 & 3.14 & -1.27 & -0.51 & -0.76 & 2.41 & -1.20 & -0.40 & -0.80 \\
\hline Chile & 3.34 & -2.13 & 0.73 & -2.86 & 2.58 & -1.83 & 0.57 & -2.40 & 2.89 & -0.72 & 0.56 & -1.28 \\
\hline Colombia & 5.58 & 0.11 & 0.38 & -0.27 & 5.85 & 1.44 & 0.38 & 1.06 & 5.72 & 2.11 & 0.36 & 1.75 \\
\hline Argentina & 4.66 & -0.81 & 0.57 & -1.38 & 3.26 & -1.15 & 0.41 & -1.56 & 2.99 & -0.62 & 0.37 & -0.98 \\
\hline
\end{tabular}

Table 6. 14 day LCFR - Difference Decomposition For India and Comparison Countries. Sources. Distribution of cases and deaths from Tables 3 and 7. These, along with overall CFRs from[20], are combined and applied to the decomposition formula (1) to obtain Incidence Effects (IE) and Fatality Effects (FE).

is no growth in the disease in recent months (at least on official paper), and the latter despite fast epidemic growth because India's epidemic has seen even faster growth. The one country that appears to be doing distinctly worse is Colombia, which is also experiencing rapid growth in cases, and - at the later dates - is an over-predictor in both Tables 2 and 5 .

4.2. The Decomposition Exercise of Section 3 Revisited, with Lagged CFR. Lagged CFRs can also be taken to the decomposition exercise of Section 3. We do so in Table 6. The structure is exactly the same as in Table 5. We study three dates - June 20, July 10 and July 30. This time we construct all case fatality rates using a fourteen day lag, the idea being that deaths at day $t$ are related to infection at day $t-18$ or thereabouts, and allowing for a "detection lag" of four days running the opposite way. (The findings are robust to different lags; see Table 8 in the Appendix for an example using ten-day lags).

The first column of numbers in this table lists lagged CFR by country, and the second column records the raw difference between the comparison country and India. Negative numbers highlighted in blue indicate that the comparison country is "doing better" than India, either in the CFR itself or in terms of the fatality effect (or both). Compared to 
Table 5, India's aggregate LCFR now edges closer to the comparison countries just on account of the lag alone. This raw difference is broken up into an incidence and fatality effect, just as in in Table 5. Now there is a larger set of fatality effects that are negative, suggesting that once lagged fatalities are introduced, the average of age-specific fatalities - with weights equal to the average incidence of cases across India and the comparison country — is even less likely to be in India's favor.

\section{Summary \& Discussion}

India's case fatality rates under covid-19 are very low, relative to the world average and especially relative to those of other countries. While these low rates have been cited as evidence for India's infrastructural resistance to the disease, it is a widely-held suspicion that India's age distribution (skewed in favor of the young) has something to do with it; see, for instance, Mukhopadhayay [15] and Ray and Subramanian [19]. This paper provides precise quantitative confirmation of that suspicion by systematically comparing India to a set of comparison countries from over the world.

The findings in this paper confirm a reservation expressed by many researchers into covid mortality: that when we fail to account for age-specific dispersion in the distribution of covid-19 cases and deaths (which is the case with the CFR), this does make a difference to our assessment of how well or otherwise any given society has confronted the pandemic. The proposition is not just a matter of academic interest: it has implications for the assessment of both the intrinsic and comparative performance of countries in addressing the phenomenon of covid mortality.

Our evaluation of India's experience suggests that the country's record is a good deal less flattering than a reliance solely on a measure of central tendency such as the case fatality rate would indicate. We've used age-specific fatality rates from comparison countries, coupled with India's distribution of covid-19 cases (which mirrors India's demographic structure) to "predict" what India's CFR would be with those age-specific rates. In most cases, those predictions are lower than India's actual performance, suggesting that India's CFR is, if anything, too high rather than too low. The general point, then, is to guard against misplaced complaisance (or panic, as the case may be) that could arise from an exclusive concern with the overall CFR, because crude aggregates often hide the fact that the news may be worse (or better, as the case may be) than it appears to be. 
Our specific approach does not entirely rely on prediction. We supplement the prediction exercises by the application of a decomposition technique developed by Shorrocks [24], the outcome of which coincides with a factorization procedure advanced by Kitagawa [13] for demographic contexts - one that has been employed to analyze differences in case fatality rates by Dudel et al [6], and in the present paper. While this approach needs access to more data that the prediction exercises do, it allows richer insights into crosscountry CFR differences by breaking them up into estimates of age-based incidence and age-based fatality. In principle, this exercise could be applied not just across countries but over time, as the disease wears on and we have access to more data.

The analysis presented here also attempts to account for a specific epidemiological feature; namely, that there is a time lag between the occurrence of infection and the occurrence of death. Therefore, rapid growth in the number of cases will tend to depress the case-fatality rates if contemporaneous statistics of deaths and cases are employed in computing those rates. That in itself comes as no surprise. The question is how this affects cross-country comparisons. We return to both the prediction and decomposition exercises, this time with lagged CFR, and it turns out that India's relative performance generally worsens. Indeed, the gap between lagged CFR and the CFR is so striking that if we were to go by the conceptually more appropriate former measure, then there is no longer a "low" Indian covid mortality rate asking to be decoded: it is, simply, large.

Whether for reasons of failure in accounting for age-distributions or time lags, India's covid-19 experience does not speak to its successful management from the points of view of human development and capability achievement. At the very least, there is reason to believe that an undiscriminating employment of the raw CFR as an indicator of success deserves to be treated with some skepticism. It seems to be important to assert this when both objective appraisal and fair accountability are threatened by summary indicators of performance that are inadequate or misleading, and when such summary measures are employed to their advantage by politicians and policy-makers.

Finally, our concern endorses the call for the timely release of data beyond case and death counts. It is imperative that detailed data disaggregated by age and other relevant demographic attributes be collected, released, and placed in the public domain. This can only enable the scientific community at large to better assess the situation unfolding before us in this unprecedented time, and to participate more meaningfully in the formulation, implementation, and monitoring of informed policies aimed at mitigation and containment. 


\section{Appendix}

5.1. Case and Death Distribution Over Age Groups. All comparisons in this paper are made relative to 13 countries and Bavaria. We use data from Bavaria instead of Germany because the latter spans a coarser age classification. The distributions of cases and deaths, along with the latest date for which we have data, are listed below.

\begin{tabular}{|c|c|c|c|c|c|c|c|c|c|c|}
\hline & & \multicolumn{9}{|c|}{ Age Group } \\
\hline & & $0-9$ & $10-19$ & $20-29$ & $30-39$ & $40-49$ & $50-59$ & $60-69$ & $70-79$ & $80+$ \\
\hline \multirow[t]{2}{*}{ China 11 Feb } & Cases (\%) & 0.9 & 1.2 & 8.1 & 17.0 & 19.2 & 22.4 & 19.2 & 8.8 & 3.2 \\
\hline & Deaths (\%) & 0.0 & 0.1 & 0.7 & 1.8 & 3.7 & 12.7 & 30.2 & 30.5 & 20.3 \\
\hline \multirow[t]{2}{*}{ S. Korea 02 Aug } & Cases (\%) & 1.7 & 5.4 & 25.2 & 12.7 & 13.5 & 17.6 & 13.0 & 6.6 & 4.2 \\
\hline & Deaths (\%) & 0.0 & 0.0 & 0.0 & 0.7 & 1.0 & 5.3 & 13.6 & 29.9 & 49.5 \\
\hline \multirow[t]{2}{*}{ Japan 29 Jul } & Cases $(\%)$ & 1.8 & 3.8 & 28.1 & 17.1 & 14.1 & 13.0 & 8.2 & 6.9 & 7.1 \\
\hline & Deaths (\%) & 0.0 & 0.0 & 0.1 & 0.4 & 1.4 & 3.3 & 10.6 & 27.3 & 56.9 \\
\hline \multirow{2}{*}{ Philippines 02 Aug } & Cases (\%) & 2.7 & 4.5 & 25.2 & 23.7 & 16.4 & 13.4 & 8.6 & 4.0 & 1.5 \\
\hline & Deaths (\%) & 1.5 & 1.1 & 2.5 & 4.7 & 9.6 & 19.5 & 28.5 & 22.0 & 10.7 \\
\hline \multirow[t]{2}{*}{ Netherlands 03 Jun } & Cases (\%) & 0.3 & 1.4 & 9.6 & 9.0 & 11.6 & 18.3 & 12.9 & 13.4 & 23.5 \\
\hline & Deaths (\%) & 0.0 & 0.0 & 0.1 & 0.2 & 0.5 & 2.4 & 8.2 & 26.9 & 61.8 \\
\hline \multirow[t]{2}{*}{ Italy $21 \mathrm{Jul}$} & Cases (\%) & 1.0 & 1.7 & 6.0 & 8.1 & 13.1 & 17.8 & 13.2 & 14.1 & 24.9 \\
\hline & Deaths (\%) & 0.0 & 0.0 & 0.1 & 0.2 & 0.9 & 3.5 & 10.1 & 26.3 & 59.0 \\
\hline \multirow[t]{2}{*}{ Spain 18 May } & Cases (\%) & 0.4 & 0.7 & 5.6 & 9.5 & 14.7 & 17.9 & 14.4 & 13.6 & 23.3 \\
\hline & Deaths (\%) & 0.0 & 0.0 & 0.1 & 0.3 & 1.1 & 3.2 & 8.8 & 24.1 & 62.3 \\
\hline \multirow[t]{2}{*}{ Bavaria 02 Aug } & Cases (\%) & 3.2 & 6.3 & 16.1 & 14.0 & 15.1 & 19.1 & 9.8 & 6.3 & 10.3 \\
\hline & Deaths (\%) & 0.0 & 0.0 & 0.2 & 0.2 & 0.6 & 3.7 & 9.9 & 25.8 & 59.6 \\
\hline \multirow[t]{2}{*}{ Sweden 02 Aug } & Cases $(\%)$ & 0.6 & 4.2 & 14.8 & 15.4 & 16.7 & 18.1 & 10.4 & 7.3 & 12.5 \\
\hline & Deaths (\%) & 0.0 & 0.0 & 0.0 & 0.0 & 0.8 & 2.8 & 6.9 & 21.6 & 67.9 \\
\hline \multirow[t]{2}{*}{ Switzerland 02 Aug } & Cases (\%) & 0.8 & 3.6 & 14.4 & 14.3 & 15.5 & 19.5 & 11.6 & 8.6 & 11.8 \\
\hline & Deaths (\%) & 0.1 & 0.0 & 0.0 & 0.3 & 0.4 & 2.4 & 7.6 & 20.3 & 69.0 \\
\hline \multirow[t]{2}{*}{ S. Africa 28 May } & Cases (\%) & 2.8 & 4.2 & 19.5 & 28.3 & 21.1 & 13.8 & 6.1 & 2.8 & 1.5 \\
\hline & Deaths (\%) & 0.4 & 0.2 & 0.7 & 5.7 & 10.6 & 25.0 & 26.5 & 19.6 & 11.4 \\
\hline \multirow[t]{2}{*}{ Chile $^{* *} 02$ Aug } & Cases (\%) & 3.3 & 5.0 & 20.6 & 22.3 & 17.0 & 15.6 & 9.0 & 4.5 & 2.8 \\
\hline & Deaths (\%) & -- & ---2.3 & $3--$ & - & 3.5 & 10.5 & 21.4 & 28.0 & 34.4 \\
\hline \multirow[t]{2}{*}{ Colombia $30 \mathrm{Jul}$} & Cases (\%) & 3.7 & 6.4 & 21.9 & 23.7 & 16.4 & 13.2 & 7.9 & 4.2 & 2.7 \\
\hline & Deaths (\%) & 0.2 & 0.1 & 1.3 & 3.2 & 7.3 & 14.2 & 23.1 & 25.1 & 25.7 \\
\hline \multirow[t]{2}{*}{ Argentina* 02 Aug } & Cases (\%) & 4.7 & 6.9 & 20.3 & 23.0 & 18.3 & 12.5 & 6.6 & 3.7 & 4.0 \\
\hline & Deaths (\%) & 0.2 & 0.2 & 0.8 & 2.1 & 5.0 & 9.8 & 17.9 & 24.5 & 39.6 \\
\hline
\end{tabular}

Table 7. Case and Death Distributions by Age for Comparison Countries. Sources. Situation reports, Press Reports or Covid -19 Dashboard of respective countries, as listed under Appendix 5.5. Notes. ${ }^{*}$ For Argentina, the distribution of deaths is imputed using equivalent data on distribution of cases and age-specific CFRs. ${ }^{* *}$ For Chile, the age-specific CFRs in all age groups between 0-39 are assumed to be equal. 
5.2. Interpolation of India's Distribution of Deaths Over 10-Year Age Groups. For the decomposition exercises undertaken in Sections 3 and 4, we use distributions of cases and deaths defined over 10-yr age brackets for the comparison countries. For India, detailed age-specific information is hard to come by. To complement the available distribution of cases in India (as of April 30, 2020) defined over the narrow 10-year age brackets [7], we interpolate the density of deaths for 10-year brackets using the death distribution over 15-year age brackets, made available by the Indian Government, as described below.

Mohanty et al [14] actually report the distribution of cases and deaths as of 9 May, 2020 using five-year age brackets. Normally, this would suffice for our purposes. However, this information is available for a total of just 7191 cases and 511 deaths recorded in a crowd-sourced patient level database [9]. We are concerned about this distribution as it appears to come from a non-random sample, the details of which are unclear to us. So we do not use it. However, we sparingly use the relative death rates across neighboring age groups in their data as a way of disaggregating the Ministry-issued data.

On July 08, 2020, the Indian Ministry of Health and Family Welfare provided a press release describing the distribution of covid-19 deaths over six 15-yr age brackets: 0-14: 1\%, 15-29: $3 \%, 30-44: 11 \%, 45-59: 32 \%, 60-74: 39 \%$ and $75+: 14 \%$. If $I^{n}$ is the set of $n$-year age groups, call this Ministry distribution $D_{1}: I^{15} \rightarrow[0,100]$, and the Mohanty et al distribution $D_{2}: I^{5} \rightarrow[0,100]$. Use $D_{2}$ to generate 10- and 15-year age distributions by simple aggregation:

$$
D_{2}^{m}(i)=\sum_{k \in I^{5} \mid k \subset i} D_{2}(k)
$$

for $m \in\{10,15\}$. Now apportion the relative weights from these distribution to the Ministry figures. Formally, define a matrix $W$ of dimension $\left|I^{10}\right| \times\left|I^{15}\right|$ with a typical element $w_{i j}$ given by

$$
w_{i j}= \begin{cases}\frac{D_{2}^{10}(i)}{D_{2}^{15}(j)} & \text { if } i \subset j \\ 0 & \text { if } i \not \subset j\end{cases}
$$

The interpolated density for 10-year age groups for the distribution of deaths based on $D_{1}$ is then given by $\tilde{D}_{1}^{10}=W D_{1}$. The distribution of deaths thus obtained is recorded in Table 3. 
5.3. Stability of the Age Distribution of Cases and Deaths. Figures 3-6 plot the age distributions of cases and deaths for select countries as obtained at different points in time. These countries are distinguished by the fact that we were able to obtain distributions of cases and deaths over 10-year age groups for several dates spanning a few months. Panel (a) graphs the age distributions of cases and Panel (b) graphs the age distributions of deaths. The graph depicted in boldface in each figure represents the latest distribution used for our analysis and listed under Table 7, while the distributions as of previous dates are depicted in grey.

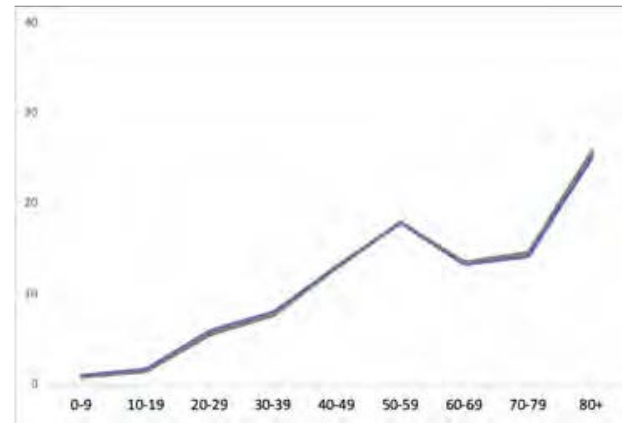

(a)

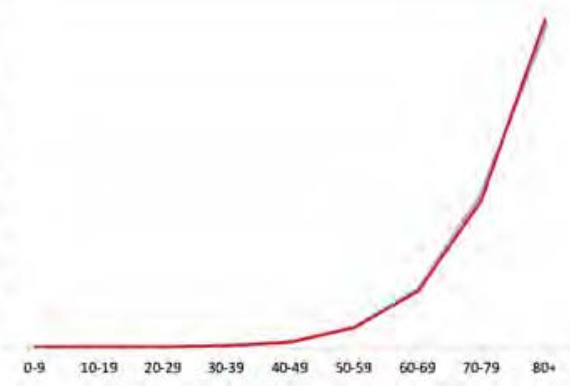

(b)

Figure 3. Italy. Panels (a) and (b) plot the age distribution of cases and deaths, respectively, for the dates 21 July, 30 June, 09 June, 20 May and 14 May 2020.

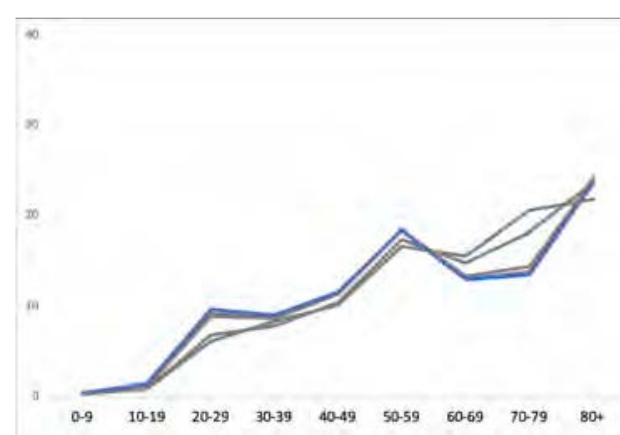

(a)

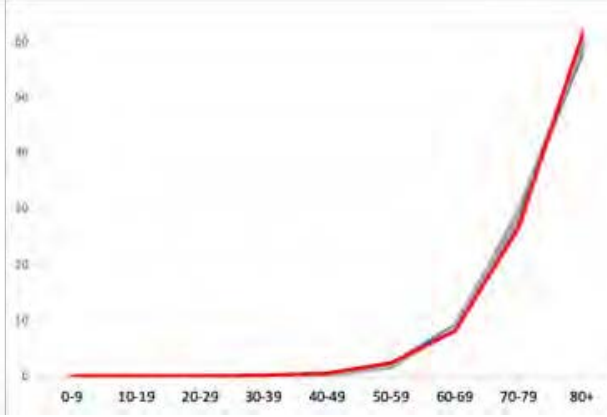

(b)

Figure 4. Netherlands. Panels (a) and (b) plot the age distribution of cases and deaths, respectively, for the dates 03 June, 20 May, 01 May, 10 April and 30 March 2020. 


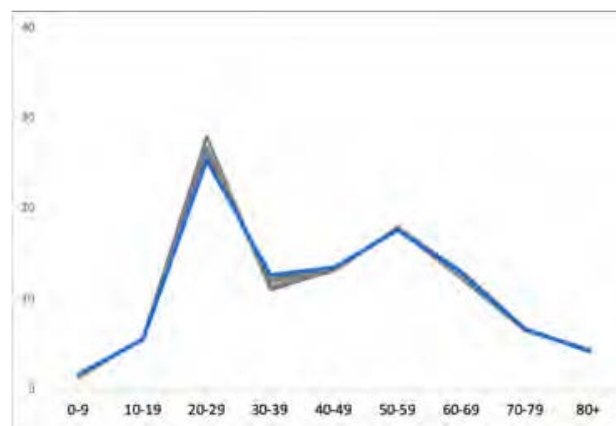

(a)

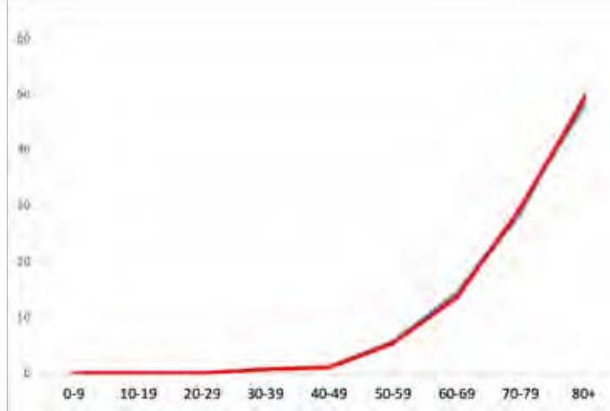

(b)

Figure 5. South Korea. Panels (a) and (b) plot the age distribution of cases and deaths, respectively, for the dates 02 August, 20 July, 10 July, 20 June and 20 May 2020.

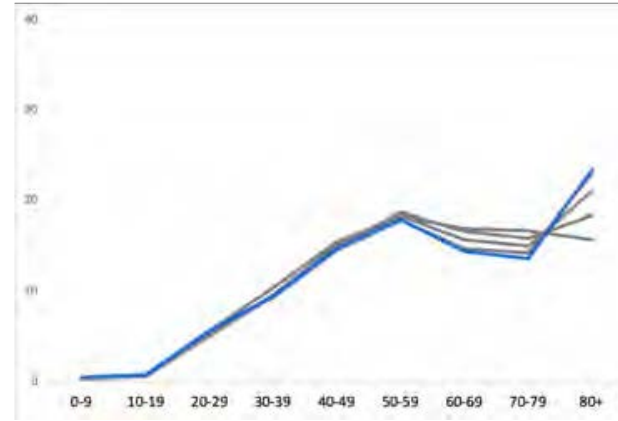

(a)

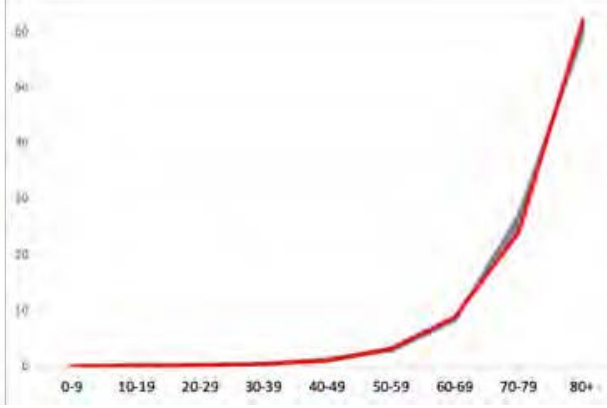

(b)

Figure 6. Spain. Panels (a) and (b) plot the age distribution of cases and deaths, respectively, for the dates 18 May, 30 April, 20 April, 10 April and 30 March 2020.

As is apparent from the uncannily coinciding curves, barring initial phases of the pandemic, the distribution of cases and deaths have been largely stable over time. (This assumes, of course, that the relevant dashboards have been fully updated and no other procedure is being followed.)

We recognize that these four countries are neither representative of the developing countries in our comparison pool nor of the countries with a younger demographic structure, such as Argentina, Colombia, India and South Africa. However, they do reflect a heterogeneous variety of covid-19 experiences. In addition to this, the dates over which we have plotted the distributions span a considerably large period of the epidemiological phase so far. While at one level, this stability is not surprising, that 
could change with qualitatively different testing regimes, differences in response to mitigation strategies, exposure to risk stemming from a change in lockdown policy, and so on.

5.4. Decomposition with 10-Day Lagged CFR. Table 8 repeats the decomposition exercise of Section 3 using 10-day lagged CFRs. The 10-day LCFRs reported in the first column are lower than the 14-day LCFRs reported in Table 6, for obvious reasons. For countries such as India, Colombia and Argentina with higher growth rate of cases, the difference between the 14-day and 10-day LCFR is sizable in contrast to countries such as South Korea and Japan which have low case growth.

Despite this relative edge in depressed fatality ratios, India still fares poorly relative to several countries in the matter of age-specific mortality, lending support to the inferences made previously on the basis of Table 6 .

\begin{tabular}{lrrrr|rrrr|rrrrr}
\hline & \multicolumn{9}{c}{ 20 June } & \multicolumn{7}{c}{ 10 July } & & \multicolumn{4}{c}{ 30 July } \\
\cline { 2 - 12 } Country & LCFR & Diff & \multicolumn{1}{c}{ IE } & FE & LCFR & Diff & IE & FE & LCFR & Diff & IE & FE \\
\hline India & $\mathbf{4 . 6 8}$ & 0.00 & - & - & $\mathbf{3 . 8 1}$ & 0.00 & - & - & $\mathbf{3 . 1 3}$ & 0.00 & - & - \\
China & 5.51 & 0.83 & 3.04 & -2.22 & 5.47 & 1.66 & 2.72 & -1.05 & 5.44 & 2.31 & 2.46 & -0.14 \\
S. Korea & 2.35 & -2.33 & 1.55 & -3.88 & 2.25 & -1.56 & 1.35 & -2.91 & 2.18 & -0.95 & 1.19 & -2.14 \\
Japan & 5.52 & 0.84 & 2.45 & -1.61 & 5.28 & 1.47 & 2.22 & -0.75 & 4.00 & 0.87 & 1.72 & -0.86 \\
Philippines & 4.92 & 0.24 & -0.11 & 0.34 & 3.62 & -0.19 & -0.09 & -0.11 & 2.91 & -0.22 & -0.07 & -0.15 \\
Netherlands & 12.69 & 8.01 & 9.24 & -1.23 & 12.22 & 8.41 & 8.27 & 0.13 & 11.88 & 8.75 & 7.53 & 1.22 \\
Italy & 14.67 & 9.99 & 10.17 & -0.18 & 14.53 & 10.72 & 9.29 & 1.43 & 14.37 & 11.24 & 8.58 & 2.66 \\
Spain & 11.69 & 7.01 & 8.89 & -1.88 & 11.39 & 7.58 & 7.98 & -0.40 & 10.74 & 7.61 & 7.10 & 0.52 \\
Bavaria & 5.40 & 0.72 & 3.31 & -2.58 & 5.39 & 1.58 & 3.01 & -1.43 & 5.27 & 2.41 & 2.74 & -0.60 \\
Sweden & 11.00 & 6.32 & 6.04 & 0.28 & 8.13 & 4.32 & 4.61 & -0.30 & 7.41 & 4.28 & 4.06 & 0.23 \\
Switzerland & 5.43 & 0.75 & 4.19 & -3.45 & 5.34 & 1.53 & 3.76 & -2.23 & 5.08 & 1.95 & 3.35 & -1.39 \\
S. Africa & 3.46 & -1.22 & -0.55 & -0.68 & 2.58 & -1.23 & -0.42 & -0.81 & 2.06 & -1.07 & -0.34 & -0.73 \\
Chile** & 2.87 & -1.81 & 0.62 & -2.44 & 2.42 & -1.39 & 0.52 & -1.91 & 2.80 & -0.33 & 0.52 & -0.84 \\
Colombia & 4.86 & 0.18 & 0.33 & -0.15 & 4.96 & 1.15 & 0.32 & 0.82 & 4.79 & 1.66 & 0.30 & 1.36 \\
Argentina & 3.96 & -0.72 & 0.49 & -1.21 & 2.74 & -1.07 & 0.35 & -1.42 & 2.61 & -0.52 & 0.32 & -0.84 \\
\hline
\end{tabular}

Table 8. 10 day LCFR - Difference Decomposition For India and Comparison Countries. Sources. Distribution of cases and deaths from Tables 3 and 7. These, along with overall CFRs from [20], are combined and applied to the decomposition formula (1) to obtain Incidence Effects (IE) and Fatality Effects (FE).

5.5. Data Sources. Table 9 lists the papers, situation reports and various national dashboards from which we have obtained the data on distributions of cases and deaths recorded in Table 7. 


\begin{tabular}{rll}
\hline Country & Data & Sources \\
\hline India & Distribution of Cases & ICMR COVID Study Group et al (IJMR 2020) [7] \\
China & Distribution of Deaths & Ministry Press Release (TOI) [4] \\
South Korea & Distribution of Cases and Deaths & China CDC Weekly (2020) [25] \\
Japan & Distribution of Cases and Deaths & Korea CDC Press Release [5] \\
Philippines & Distribution of Cases and Deaths & COVID-19 Tracker https://www.doh.gov.ph/covid19tracker \\
Netherlands & Distribution of Cases and Deaths & RIVM [17] \\
Italy & Distribution of Cases and Deaths & Istituto Superiore di Sanità (ISS) [22] \\
Spain & Distribution of Cases and Deaths & Ministerio de Sanidad [21] \\
Bavaria & Distribution of Cases and Deaths & Bavarian State Office for Health and Food Safety [8] \\
Bavaria & Counts of Cases and Deaths & Daily Situation Report, Robert Koch Institute [10] \\
Sweden & Distribution of Cases and Deaths & https://experience.arcgis.com/experience/09f821667ce64bf7be6f9f87457ed9aa \\
Switzerland & Distribution of Cases and Deaths & https://datawrapper.dwcdn.net/IJC8v/144/ \\
South Africa & Distribution of Cases and Deaths & Department of Health - Press Release and Notices [3] \\
Chile & Distribution of Cases and Deaths & https://www.gob.cl/coronavirus/cifrasoficiales/ \\
Colombia & Distribution of Cases and Deaths & https://www.ins.gov.co/Noticias/Paginas/Coronavirus.aspx \\
Argentina & Distribution of Cases and Deaths & https://www.argentina.gob.ar/salud/coronavirus-CovID-19/sala-situacion \\
\hline
\end{tabular}

Table 9. List of Data Sources for Distribution of Cases and Deaths reported under Table 7 


\section{References}

[1] Siwan Anderson and Debraj Ray. "Missing Women: Age and Disease". Review of Economic Studies 77 (2010), pp. 1262-1300. Dor: 10.1111/j.1467-937X.2010.00609.x.

[2] Rupam Bhattacharyya, Ritwik Bhaduri, Ritoban Kundu, Maxwell Salvatore, and Bhramar Mukherjee. "Reconciling epidemiological models with misclassified case-counts for SARS-CoV-2 with seroprevalence surveys: A case study in Delhi, India". medRxiv (2020). Dor: https://doi.org/10.1101/2020.07.31.20166249.

[3] Department of Health, Republic of South Africa. "Update on Covid-19: Press Release and Notices". COVID-19 Corona Virus South African Resource Portal (2020). URL: https://sacoronavirus.co.za/2020/05/29/update-on-covid-19-28th-may-2020/.

[4] Sushmi Dey. 43\% of Covid-19 deaths in India in 30-59 yrs age band. July 10, 2020. URL: https://timesofindia.indiatimes.com/india/43-of-covid-19-deaths-in-india-in-30-59-yrs-ageband/articleshow/76882684.cms.

[5] Korean Center for Disease Control and Prevention. "Press Release - 471". KCDC (Aug 2, 2020). uRL: https://www.cdc.go.kr/board/board.es?mid=a30402000000\&bid=0030.

[6] Christian Dudel, Tim Riffe, Enrique Acosta, Alyson A. van Raalte, Cosmo Strozza, and Mikko Myrskyla. "Monitoring trends and differences in COVID-19 case fatality rates using decomposition methods: Contributions of age structure and age-specific fatality". medRxiv (2020). DoI: https://doi.org/10.1101/2020.03.31.20048397.

[7] ICMR COVID Study Group, COVID Epidemiology, Data Management Team, COVID Laboratory Team, and VRDLN Team. "Laboratory surveillance for SARSCoV-2 in India: Performance of testing \& descriptive epidemiology of detected COVID-19, January 22 - April 30, 2020". Indian Journal of Medical Research ;151:42437 (2020). URL: http://www.ijmr.org.in/text.asp?2020/151/5/424/285361.

[8] Bavarian State Office for Health and Food Safety. Overview of the number of cases of coronavirus infections in Bavaria. 2020. URL: https://www. Igl.bayern.de/gesundheit/ infektionsschutz / infektionskrankheiten_a_z/coronavirus / karte_coronavirus / index. htm \# alter_ geschlecht.

[9] COVID-19 India Dashboard Crowd Sourced Inititative (2020). URL: https://www. covid19india.org/.

[10] Robert Koch Institute. “Coronavirus Disease 2019 (COVID-19) - Situation Report of the Robert Koch Institute" (2020). URL: https://www.rki.de/DE/Content/InfAZ/N/Neuartiges_ Coronavirus/Situationsberichte/Gesamt.html. 
[11] D. Jayaraj and S. Subramanian. "The wellbeing implications of a change in the sex-ratio of a population". Social Choice and Welfare 33 (2009), pp. 129-150. Dor: 10.1007/s00355-008-0349-1.

[12] Ravi Kanbur and Diganta Mukherjee. "Premature Mortality and Poverty Measurement". Bulletin of Economic Research 59(4) (2007), pp. 339-359. Dor: https://doi.org/ 10.1111/j.0307-3378.2007.00265.x.

[13] Evelyn M. Kitagawa. "Components of a Difference Between Two Rates". Journal of the American Statistical Association 50 (272 1955), pp. 1168-1194.

[14] Sanjay Kumar Mohanty, Umakanta Sahoo, Udaya Shankar Mishra, and Manisha Dubey. "Age Pattern of Premature Mortality under varying scenarios of COVID19 Infection in India". medRxiv (June 11, 2020). Dor: https://doi.org/10.1101/2020.06.11. 20128587.

[15] Partha Mukhopadhyay. Is India's Covid-19 death rate higher than Italy's? June 11, 2020. URL: https://www.hindustantimes.com/opinion/is-india-s-covid-19-death-rate-higher-thanitaly-s/story-F73TUEHkNkDrgBT6WAeDEM.html.

[16] Samuel H. Preston, Patrick Heuveline, and Michel Guillot. Demography: Measuring and Modeling Population Processes. Oxford, UK: Blackwell, 2001.

[17] National Institute for Public Health and the Environment. "Epidemiological situation COVID-19 in the Netherlands June 3, 2020" (2020). URL: https://www. rivm.nl/documenten/epidemiologische-situatie-covid-19-in-nederland-3-juni-2020.

[18] Pallavi Pundir. "'Missing' COVID Deaths Raise Questions About India's Tracking of the Outbreak". Vice (June 14, 2020). uRL: https://www.vice.com/en_au/article/3azdv3/ missing-covid-deaths-raise-questions-about-indias-tracking-of-the-outbreak.

[19] Debraj Ray and S. Subramanian. "India's Lockdown: An Interim Report". CAGE working paper No. 476 (May 20, 2020). URL: https://warwick.ac.uk/fac/soc/economics/ research/centres/cage/manage/publications/wp476.2020.pdf.

[20] Max Roser, Hannah Ritchie, Esteban Ortiz-Ospina, and Joe Hasell. "Coronavirus Pandemic (COVID-19)". Our World in Data (2020). URL: https://ourworldindata.org/ coronavirus.

[21] Consumo y Bienestar Social Ministerio de Sanidad. “Actualización no 109. Enfermedad por el coronavirus (COVID-19)" (2020). URL: https://www. mscbs.gob. es/profesionales/saludPublica/ccayes/alertasActual/nCov-China/documentos/Actualizacion_109_ COVID-19.pdf. 
[22] Istituto Superiore di Sanità (ISS). "COVID-19 epidemic: National Update" (July 21, 2020). URL: https://www.epicentro.iss.it/coronavirus/bollettino/Bollettino-sorveglianza-integrataCOVID-19_21-luglio-2020.pdf.

[23] Lloyd S. Shapley. "A value for n-person games". Kuhn, H.W., Tucker, A.W. (eds.) Contributions to the Theory of Games 2 (1953).

[24] Anthony F. Shorrocks. "Decomposition procedures for distributional analysis: a unified framework based on the Shapley value". The Journal of Economic Inequality 11 (2013), pp. 99-126. Dor: https://doi.org/10.1007/s10888-011-9214-z.

[25] The Novel Coronavirus Pneumonia Emergency Response Epidemiology Team. "The Epidemiological Characteristics of an Outbreak of 2019 Novel Coronavirus Diseases (COVID-19) - China, 2020". China CDC Weekly 2(8): 113-122 (2020). Dor: 10.46234/ccdcw2020.032.

[26] United Nations, Department of Economic and Social Affairs, Population Division (2019). World Population Prospects 2019, Online Edition. Rev. 1. https://population.un.org/ wpp/Download/Standard/Population/.

[27] Robert Verity, Lucy C Okell, Ilaria Dorigatti, Peter Winskill, Charles Whittaker, Natsuko Imai, Gina Cuomo-Dannenburg, Hayley Thompson, Patrick G T Walker, Han Fu, Amy Dighe, Jamie T Griffin, Marc Baguelin, Sangeeta Bhatia, Adhiratha Boonyasiri, Anne Cori, Zulma Cucunubá, Rich FitzJohn, Katy Gaythorpe, Will Green, Arran Hamlet, Wes Hinsley, Daniel Laydon, Gemma Nedjati-Gilani, Steven Riley, Sabine van Elsland, Erik Volz, Haowei Wang, Yuanrong Wang, Xiaoyue Xi, Christl A Donnelly, Azra C Ghani, and Neil M Ferguson. "Estimates of the severity of coronavirus disease 2019: a model-based analysis". The Lancet Infectious Diseases 20(6) (2020), pp. 669-677. Dor: https://doi.org/10.1016/S1473-3099(20)30243-7. 